\title{
Towards an enhanced climate system monitoring: challenges and perspectives
}

\author{
Thomas C. Peterson ${ }^{1, *}$, Omar Baddour ${ }^{2}$ \\ ${ }^{1}$ National Climatic Data Center/NOAA, Asheville, North Carolina 28801-5001, USA \\ ${ }^{2}$ World Meteorological Organization, 1211 Geneva 2, Switzerland
}

\begin{abstract}
Climate system monitoring is more involved than just launching a new satellite and tracking the ensuing data. The most valuable data are those needed to observe essential climate variables. The data also need to go through a well-defined process, transforming the raw data into climate data records to help ensure that the information derived from these records accurately depicts how the climate is changing. A key aspect of any strategy for improving global climate system monitoring is enhancing the international exchange of climate data. The benefit of this often becomes clear as meteorological services in countries around the world improve the climate information they provide by putting it in the context of larger scale, cross-border climate signals.
\end{abstract}

KEY WORDS: Climate $\cdot$ Climate monitoring $\cdot$ Monitoring needs

\section{INTRODUCTION}

Imagine that you live in a city running low on drinking water during a prolonged drought and you are asked by water planners for advice on what the city should do differently in the long-term, that is, after this immediate crisis has ended. The answer clearly depends on whether the current drought is a once in 200 yr drought or a once in 20 yr drought. Do the long-term data, and model projections, indicate that droughts of this magnitude are becoming more frequent or less frequent? In sum, how could you possibly make the right recommendations without climate monitoring information?

A myriad of climate monitoring efforts are underway globally, regionally, nationally and even locally. Droughts are tracked across southern Africa and southern Illinois. Surface and subsurface water in the eastern Pacific Ocean is closely monitored to alert farmers in Ecuador and emergency planners in southern California of developing El Niño or La Niña conditions. Globally the World Meteorological Organization (WMO) reports on the state of the previous year's climate in a clear, multi-language 13-page document that lay readers throughout the world can understand
(WMO 2010). For a more detailed and technical annual assessment, the National Oceanic and Atmospheric Administration (NOAA) helps produce a supplement to the Bulletin of the American Meteorological Society with contributions from over 300 authors worldwide, documenting the state of the climate (Arndt et al. 2010).

\section{RESEARCH NEEDS}

\subsection{Variables to monitor}

The global climate observing system (GCOS) has determined the most important climate variables to monitor. Their essential climate variables (ECVs) were identified based on both their scientific relevance and their potential to actually be successfully monitored, if not at the present time, then within a few years.

Table 1 shows the global monitoring and documenting status of the ECVs in the annual State of the Climate report as of the end of 2009 (Baringer \& Arndt 2010). GCOS (2010) is in the process of updating the list of ECVs. Atmospheric ECVs will likely remain 
Table 1. GCOS Essential Climate Variables (ECVs) and monitoring status in the 2009 State of the Climate report (Baringer \& Arndt, 2010). 'Yes': the ECV is monitored on a global- or near global-scale and that the report includes a section describing its changes over time. 'Discussed': the ECV is explicitly discussed in this year's report, but the data are not updated through 2009 or the coverage is not global. 'No': more work needs to be done in order to monitor and document this ECV

\begin{tabular}{|c|c|c|}
\hline Compartment & ECV & Status \\
\hline \multicolumn{3}{|l|}{ Atmospheric } \\
\hline \multirow[t]{6}{*}{ Surface } & Air temperature & Yes \\
\hline & Precipitation & Yes \\
\hline & Air pressure & Yes \\
\hline & Surface radiation budget & No \\
\hline & Wind speed and direction & Discussed \\
\hline & Water vapor & No \\
\hline \multirow[t]{5}{*}{ Upper air } & Earth radiation budget & Yes \\
\hline & Upper-air temperature & Yes \\
\hline & Wind speed and direction & No \\
\hline & Water vapor & Yes \\
\hline & Cloud properties & Yes \\
\hline \multirow[t]{10}{*}{ Composition } & Carbon dioxide & Yes \\
\hline & Methane & Yes \\
\hline & Ozone & Yes \\
\hline & Nitrous oxide & Yes \\
\hline & Chlorofluorocarbons & Yes \\
\hline & Hydrochlorofluorocarbons & Yes \\
\hline & Hydrofluorocarbons & Yes \\
\hline & Sulphur hexaflurorides & Yes \\
\hline & Perfluorocarbons & No \\
\hline & Aerosol properties. & Yes \\
\hline \multicolumn{3}{|l|}{ Ocean } \\
\hline \multirow[t]{8}{*}{ Surface } & Sea surface temperature & Yes \\
\hline & Sea surface salinity & Yes \\
\hline & Sea level & Yes \\
\hline & Sea state & No \\
\hline & Sea ice & Yes \\
\hline & Current & Yes \\
\hline & Ocean color (for biological activity) & Yes \\
\hline & Carbon dioxide partial pressure & Discussed \\
\hline \multirow[t]{7}{*}{ Subsurface } & Temperature & Yes \\
\hline & Salinity & No \\
\hline & Current & Discussed \\
\hline & Nutrients & No \\
\hline & Carbon & Discussed \\
\hline & Ocean tracers & No \\
\hline & Phytoplankton & No \\
\hline \multirow[t]{17}{*}{ Terrestrial } & Soil moisture and wetness & Discussed \\
\hline & Surface ground temperature & No \\
\hline & Subsurface temperature and moisture & No \\
\hline & Snow and ice cover & Yes \\
\hline & Permafrost & Discussed \\
\hline & Glaciers and ice sheets & Discussed \\
\hline & River discharge & Discussed \\
\hline & Water use & No \\
\hline & Ground water & No \\
\hline & Lake levels & Yes \\
\hline & Albedo & No \\
\hline & Land cover (including vegetation type) & No \\
\hline & Fraction of absorbed photosynthetically & \\
\hline & active radiation & Yes \\
\hline & Leaf area index & No \\
\hline & Biomass & Discussed \\
\hline & Fire disturbance & Discussed \\
\hline
\end{tabular}

unchanged; ocean surface ECVs will gain ocean acidity; subsurface ocean ECVs will gain carbon dioxide partial pressure, oxygen, marine biodiversity and habitat properties and will have carbon removed; and the list of terrestrial ECVs will also likely include soil carbon and terrestrial biodiversity and habitat properties in the future.

\subsection{Turning data into climate data records}

To monitor the GCOS, ECVs require a wide variety of data, both satellite and in situ, from instantaneous observations in the deep ocean to monthly averages of observations high in the atmosphere. But one thing they all have in common is the need to convert the raw data into climate data records (CDRs) (GCOS 2010). CDRs have been defined as time series of measurements of sufficient length, consistency and continuity to determine climate variability and change (NRC 2004). So a key feature of CDRs, beyond the quality control that all data records undergo, is the application of adjustments to remove time-dependent biases in the data so that one can use these data in climate change analyses. For example, sea-surface temperature CDRs have adjustments to account for the change in observing practice from methods involving canvas buckets being thrown over the side to collect surface water and insertion of a thermometer into the bucket once it is brought up on deck to the use of thermometers in engine cooling water intake lines. Adjustments are made to satellite data to account for satellite drift in equatorial passing time or to account for the change from one satellite to the next. See Aguilar et al. (2003) for background information on homogeneity adjustments.

\subsection{Structural uncertainty}

Applying homogeneity adjustments to the data and then publishing an article documenting the technique and its calculated reliability is no guarantee of accuracy. In the process of building a data set, there are decisions about approaches to be used in the data set construction that impact the final product. As a result, 2 different groups working with the same data can come up with very different trends. A measure of the effects of these data set construction decisions is referred to as the structural uncertainty. Rigorous evaluations of all reasonable options in building a CDR are quite rare. So the most common approach to assessing structural uncertainty is comparing 2 or more data sets.

There is an old saying that a person with one watch always knows what time it is, but a person with 2 
watches is never sure. In climate analysis, the opposite is closer to the truth. Multiple versions of the same data give information on structural uncertainty associated with the different analyses. For example, Fig. 1 shows the temperature trend from 1979-2009 at the surface (3 data sets), from the mid-troposphere from microwave satellite data (3 data sets) and from radiosondes (4 data sets). When tropospheric temperature was primarily defined by only 1 data set, the University of Alabama in Huntsville microwave satellite data set, there was a lot of debate about why surface trends differed from tropospheric trends (see Thorne et al. 2010 for a history of this controversy). Now that there are multiple tropospheric trends from both satellite and radiosonde data sets, it is clear that one of the reasons for the difference is the large structural uncertainty in tropospheric temperature analyses and that the data set used at that time happened to be near the far end of the now current mix of analyses. The lesson is clear though: a single climate data record may not be sufficent to provide confidence in the derived understanding of how the climate is changing so the most important ECVs should have multiple independent analyses.

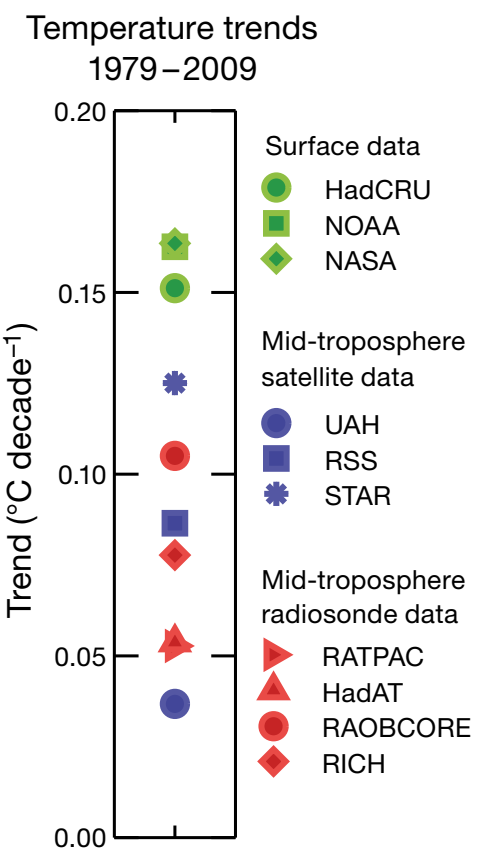

Fig. 1. Global temperature trends from 1979 through 2009 for the surface (green) and for mid-troposphere satellite (blue) and radiosonde (red) data. HadCRU: UK Hadley Centre and CRU/UEA; NOAA: NOAA/NCDC; NASA: NASA GISS; UAH: Univ. of Alabama in Huntsville; RSS: Remote Sensing Systems; STAR: NOAA/NESDIS/STAR; RATPAC: NOAA; HadAT: UK Hadley Centre; RAOBCORE: Austrian approach with break point adjustments from reanalysis; RICH: Austrian approach with break point adjustments from neighboring stations. Derived from Thorne et al. (2010)

\subsection{Physical consistency}

Multiple realizations of the same ECV is but one way to gain confidence in the analyses. Another way is through independent analysis of related variables. An example of that is given in Fig. 2. This figure shows
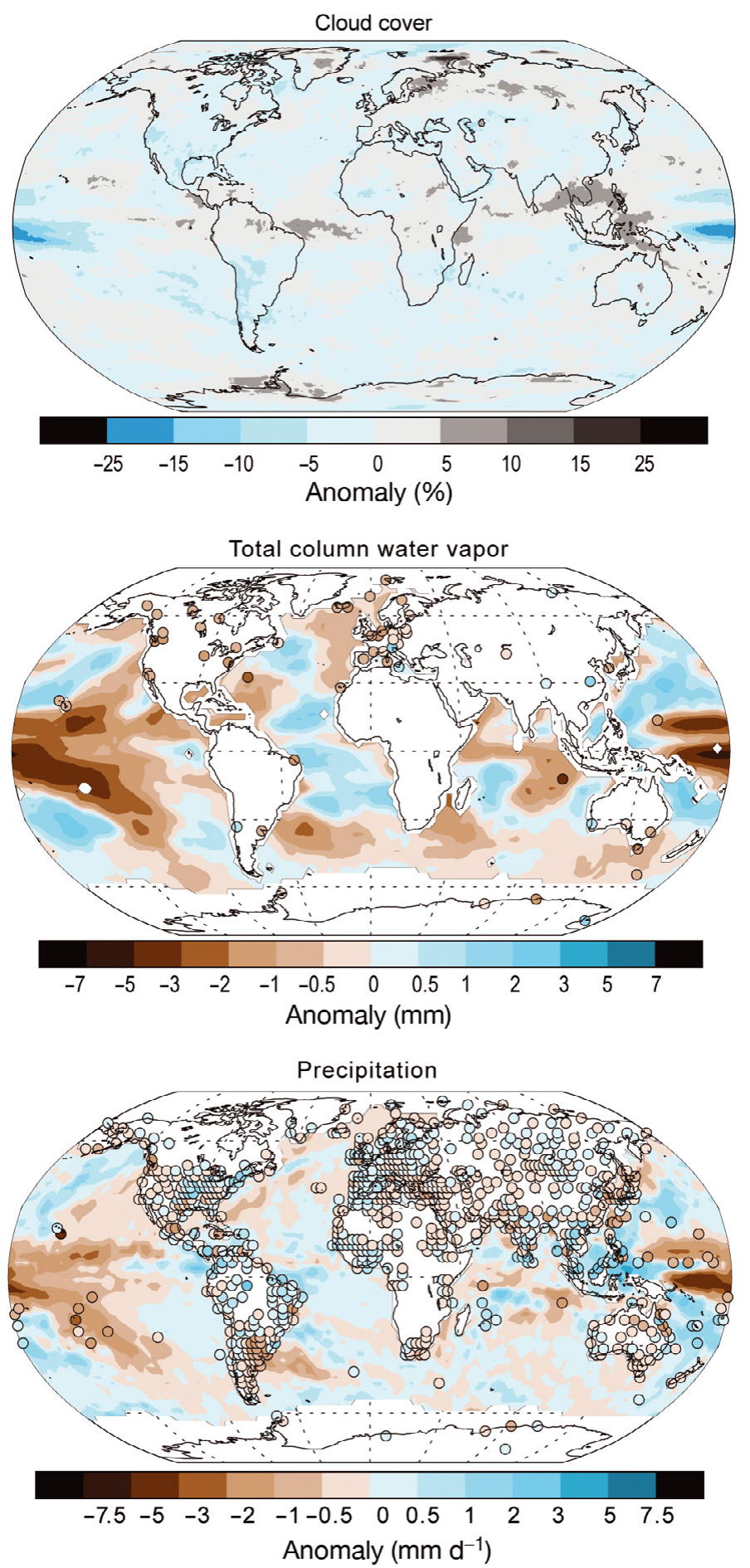

Fig. 2. Cloud cover, water vapor and precipitation anomalies for 2008, showing physically consistent patterns. From Thorne (2009) 
anomalies of cloud cover, water vapor and precipitation for 2008; these variables show physically consistent patterns, though a more rigorous test of the ECV observations would be to compare patterns of longterm trends.

\section{STRATEGIES FOR IMPROVEMENT}

\subsection{Data sets}

There are 3 key opportunities for improvement. The first is applying additional intellectual resources in the quest to build more CDRs. This is a straightforward process, but by no means trivial. For example, there are currently $>750$ million hourly and synoptic observations of wind speed and direction from several thousand stations around the world in the U.S. National Climatic Data Center/NOAA's archive. These observations encompass a wealth of information about the GCOS ECV wind speed and direction. Yet these data also have a myriad of homogeneity problems, including, but not limited to, changes in anemometer type as better equipment was installed, which may sometimes provide low wind speed observations during conditions in which the earlier equipment would have classified the conditions as calm; periodic maintenance, in which lubrication of the anemometer could cause increases in the measured wind speed; construction and vegetation growth or removal around the station, which may alter observed wind speed and direction, as well as the movement of the weather observing station. Metadata documenting these changes are often limited and primarily maintained in national archives. Therefore, to take on the task of building a global wind CDR means being willing to spend many years or even decades on a project with no guarantee of success (as attempts in 2 countries to build national homogeneous wind data sets were abandoned after the difficulties were found to be intractable). Excellent scientists willing to undertake such endeavors are as rare as institutions willing to fund them. But we only need 1 or 2 scientists working on the problem to make progress on an ECV CDR and a couple more to provide a measure of the structural uncertainty through independent analyses.

The second opportunity is developing new observing systems. Satellites are only one of the new opportunities for new data. While satellites are often the only way to provide global coverage, they have the drawbacks of limited life spans and expense. On the in situ side of observing systems, there are opportunities for both new technologies and expansion of existing technology. An example of new technology would be in the monitoring of perfluorocarbons. This chemical is on the
GCOS list of ECVs, because, molecule for molecule, it has a very strong greenhouse effect and it is very long-lived. At the present time, monitoring is difficult because perfluorocarbons are in concentrations of parts per quadrillion. New technologies that could improve its detection in very low amounts may provide a breakthrough in the next few years. In contrast, soil moisture is an ECV that has a long record of being measured, but only in limited locations. The addition of soil moisture sensors at weather observing stations throughout the world would enhance the coverage of this ECV. Unfortunately, all of these new observing opportunities would only provide time series from the present into the future.

There are many ways to enhance historical instrumental analyses. This third opportunity includes increasing the amount of data via digitization of historic records that are currently only on paper, and enhancing international exchange of historical observations and information. An increase in the available data would improve homogeneity adjustments because it would make neighboring stations available, which could be used for closer comparisons. Unfortunately, there are many institutional limitations to the international exchange of historical data. It is always dangerous to provide reasons for some other institution's behavior, because it is so difficult to fairly present a point of view that you yourself disagree with. Yet, with this caveat in mind, we suggest the 3 largest obstacles to free and open exchange of historical data below.

(1) We need credit for our work. Some countries are very willing to provide a researcher with data provided the researcher agrees to: (a) not release the data and (b) provide an acknowledgment of the source of the data. On the surface, this seems like a symbiotic approach. The researcher gets access to the data he or she needs, and the institution that has done the hard work of making the measurements, controlling the quality, providing them, etc., gets acknowledged for their efforts. At the end of the year, the institution can provide their funding agency with a list of all the people and scientific papers that used their data, which would not be possible if their data were part of a global data set instead. The problem is that, if all countries followed this approach, global analysis would grind to a halt, as every researcher would have to contact 189 separate countries seeking their data, each set of which could be in a different format.

(2) We need to sell our data. Some meteorological services are on very tight budgets. So tight, in fact, that if they did not receive revenues from the sale of their data, they might not have the resources to make and process the observations in the first place. Often there is a government policy requiring national meteorological and hydrological services (NMHSs) to earn money 
to compensate for part of their expenses. This is done not only by selling data, but also by developing and selling a variety of data-intensive climate services. As a result, the price charged for data varies dramatically from country to country, ranging from quite modest to so high that it prohibits most potential analyses. Interestingly, 'the relationship between national wealth and unit cost of data is difficult to generalize' (Hulme 1994).

(3) Because they are ours. For want of a better explanation, this classification is for countries where data sales are not a significant portion of the meteorological service's funding, yet they do not release their data. Some countries' meteorological services do not even provide academics in their own country access to their data, let alone release their data internationally.

Often, of course, the reason is a mixture of all 3.

Two notable efforts are being taken to bridge these obstacles. (1) The development of the GCOS surface network (GSN). The GSN is a limited set of approximately 1000 stations worldwide that were identified as the world's best stations for long-term climate monitoring (Peterson et al. 1997). For a station to be designated as a GSN station, a country must agree to provide the historical data from the station to the GSN Archive Center. The guiding thought behind this process is that for a limited number of stations, countries would be willing to provide historical daily temperature and precipitation data (in addition to other parameters) for a global data base, as well as internationally transmitting regular monthly summaries as CLIMAT messages (a coded message system for sending climatological data). As Figs. $3 \& 4$ indicate, this effort has met with some limited success and still has plenty of room for improvement.

(2) The key to the second effort is participation. Specifically, participation in global climate change analyses. The method adopted was holding a series of hands-on workshops around the world, where participants brought their data, controlled their quality and then analyzed the data to determine how extremes were changing (Peterson \& Manton 2008). As this work was coordinated by a team of WMO experts, the analyses for each part of the world could be fit together seamlessly, and contributed to the Intergovernmental Panel on Climate Change (IPCC) assessment (Trenberth et al. 2007). These workshops often represented the first time that individuals analyzed how the climate in their country was changing. This brought about a new appreciation for the data, which resulted in addi- tional data being digitized (see Fig. 5). While participants from most countries were not able to release their data, as that decision is made by someone above them, most were able to release indices derived from their data. So, for example, though a country might sell the actual temperature data from their station to an engineer designing a building, the researchers were able to release the number of days in a year with the maximum temperature exceeding the 90th percentile. A drawback of this approach is that the indices are not reproducible without the original data, and reproducibility is a key feature of good science (Somerville et al. 2007). On the plus side, the indices do allow for cross-border verification of changes in extremes.

In addition to these 2 efforts, there has been a notable underlying trend over the past $15 \mathrm{yr}$ of an increasing number of countries expanding the amount of monthly and daily historical climate data that they freely make available to researchers worldwide.

\subsection{Monitoring for improved climate services}

While global climate monitoring has historically focused on the data and analysis required to determine how the global mean temperature has been changing, in recent years there has been an increased demand for climate monitoring information that could also help efforts to enable countries to cope with short-term climate variability. The recent scientific findings related to the increase in the frequency and intensity of ex- 


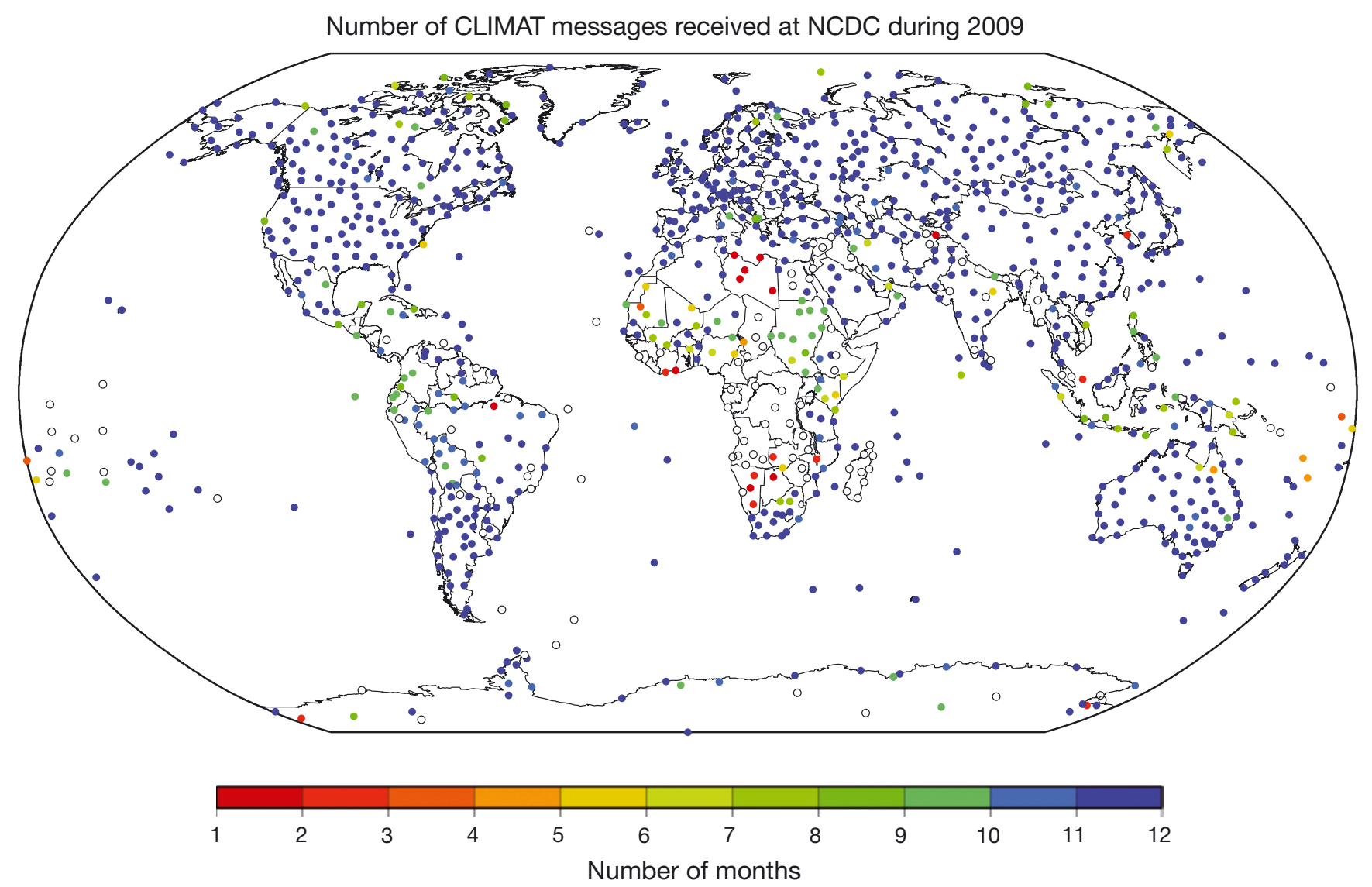

Fig. 4. Number of CLIMAT messages from GCOS surface network stations received at the National Climatic Data Center's (NCDC) GCOS Lead Center in 2009

treme climate events with high societal impacts has heightened the urgency for this information. For example, the IPCC (Trenberth et al. 2007) reports a number of observed changes in extremes over the past several decades based on instrumental series. In recent decades, most land areas of the world have experienced fewer cold days/nights (and frost days) and more hot days/nights (and heat waves). Heavy precipitation events have increased over most areas, leading to a larger proportion of annual total rainfall from heavy precipitation.

NMHSs have the responsibility of providing information on weather and climate extremes, including statistical information, such as frequency tables for the

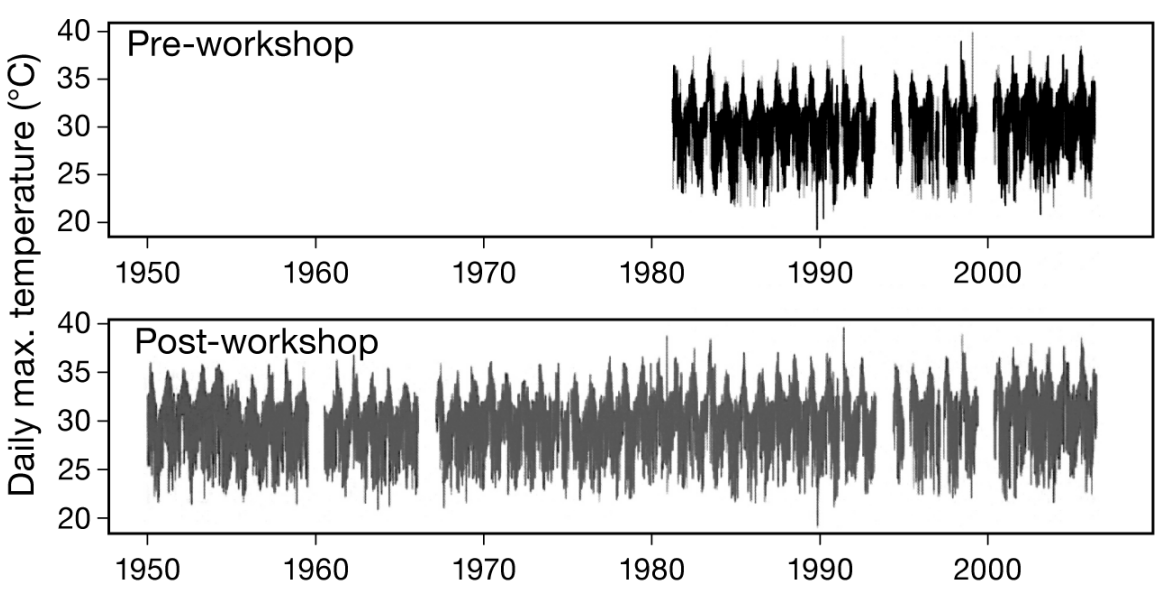

Fig. 5. Digital daily maximum temperature from Berberati, Central African Republic. Black: before the regional climate change workshop; gray: a few months after the workshop. The improvements are a result of a digitization effort. From Aguilar et al. (2009) 
occurrence of extremes, and forecasts every few hours or weekly. However, they frequently face challenges in providing adequate answers on how these extreme events are changing in frequency and intensity with the changing climate. This type of knowledge has been addressed recently by climate experts (Klein Tank et al. 2009) with the aim of enhancing the capabilities of meteorological services to meet these challenges and to provide new services for decision- and policy-makers related to climate risk management and adaptation measures and strategies.

To accurately monitor extreme events, NMHSs need the following:

- well-managed observation networks ensuring the coverage and resolution required for short-term climate monitoring on a $10 \mathrm{~d}$ to monthly or seasonal basis

- a sound climate data infrastructure for recovering old records, which often are at risk of being lost or degraded, and thus prevented access to important information on past climate

- metadata detailed enough for the descriptions of observation practices to be used to guide homogeneity analyses and adjustments

- the sharing of network metadata with the data users and research community

- the putting together of all these pieces in order to facilitate the use of historical climate information to assess the observed changes in the intensity and frequency of extreme events

- the ability to perform quick analysis on current climate anomalies, including their initiation, expected end and the possible negative impacts they may induce on socio-economic activities.

These elements constitute the basic requirements for implementing both sound climate monitoring and climate watch systems. These systems would help enable meteorological services to provide useful climate services to meet the increasing demand for information on climate extremes and related events required for planning and risk management on multiple time scales (Baddour \& Bessemoulin 2009).

\section{CONCLUSIONS}

At the 2009 meeting in Copenhagen of the United Nations Framework Convention on Climate Change, speaker after speaker reaffirmed that climate change is a global phenomenon-that we are all in this together. Yet, some of the obstacles climate system monitoring faces are a direct result of local, parochial concerns outweighing global. To improve climate monitoring, organizations like GCOS, the World Climate Research Program and the WMO Commission for Climatology are working hard to coordinate and col- laborate on climate monitoring globally, while meteorological services are working hard to provide needed climate information for their countries. Despite this hard work, these international efforts have met with only limited success in improving the international availability of in situ data. To get the climate community to work together to create a single, clean, comprehensive and open repository of in situ temperature data, the United Kingdom, in collaboration with these international organizations, is hosting a major surface temperature data meeting scheduled for September 2010 (Stott \& Thorne 2010). Improving climate observing networks and related data management to enable countries to provide the climate monitoring and services required at regional and national levels will also add value to the ongoing international efforts to meet the evolving requirements for higher resolution climate data for climate change assessment.

Acknowledgements. The authors thank Dr. Matthew Menne for creating Figs. $3 \& 4$ as part of a report to the GCOS atmospheric observation panel for climate on the status of the GCOS Archive Center.

\section{LITERATURE CITED}

Aguilar E, Auer I, Brunet M, Peterson TC, Wieringa J (2003) Guidelines on climate metadata and homogenization. WCDMP No. 53, WMO-TD No. 1186, World Meteorological Organization, Geneva

Aguilar E, Barry A, Brunet M, Ekang L and others (2009) Changes in temperature and precipitation extremes in western Central Africa, Guinea Conakry and Zimbabwe, 1955-2006. J Geophys Res 114:D02115. doi:10.1029/2008 JD011010

Arndt DS, Baringer MO, Johnson MR (eds) (2010) State of the climate in 2009. Bull Am Meteorol Soc 91:S1-S224

Baddour O, Bessemoulin P (2009) Climate watch-purpose and requirements. WMO. Climate sense. Tudor Rose, Leicester, p 190-193

Baringer MO, Arndt DS (2010) Introduction. In: Arndt D, Baringer $\mathrm{MO}$, Johnson $\mathrm{M}$ (eds) State of the climate in 2009. Bull Am Meteorol Soc 91:S14-S18

GCOS (Global Climate Observing System) (2010) Implementation plan for the Global Observing System for climate in support of the UNFCCC. World Meteorological Organization, Geneva [Draft 1]

Hulme M (1994) The cost of climate data: a European experience. Weather 49:168-175

Klein Tank AMG, Zwiers FW, Zhang X (2009) Guidelines on analysis of extremes in a changing climate in support of informed decision for adaptation. WCDMP No. 72, WMO-TD No. 1500, World Meteorological Organization, Geneva

National Research Council (2004) Climate data records from environmental satellites. National Academy Press, Washington, DC

> Peterson TC, Manton MJ (2008) Monitoring changes in climate extremes: a tale of international collaboration. Bull Am Meteorol Soc 89:1266-1271

Peterson T, Daan H, Jones P (1997) Initial selection of a GCOS 
surface network. Bull Am Meteorol Soc 78:2145-2152

Somerville R, Le Treut H, Cubasch U, Ding Y and others (2007) Historical overview of climate change. In: Solomon S, Qin D, Manning M, Chen Z and others (eds) Climate change 2007: the physical science basis. Contribution of Working Group I to the 4 th assessment report of the Intergovernmental Panel on Climate Change. Cambridge University Press, Cambridge

Stott PA, Thorne PW (2010) How best to log local temperatures? Nature 465:158-159

Thorne PW (2009) Global climate. In: State of the climate in 2008. Bull Am Meteorol Soc 90:S17-S46

Thorne PW, Lanzante JR, Peterson TC, Seidel DJ, Shine KP

Submitted: April 26, 2010; Accepted: October 18, 2010
(2010) Tropospheric temperature trends: history of an ongoing controversy. Wiley Interdiscip Rev Clim Change 2: $66-88$

Trenberth KE, Jones PD, Ambenje P, Bojariu R and others (2007) Observations: surface and atmospheric climate change. In: Solomon S, Qin D, Manning M, Chen Z and others (eds) Climate change 2007: the physical science basis. Contribution of Working Group I to the 4th assessment report of the Intergovernmental Panel on Climate Change. Cambridge University Press, Cambridge

World Meteorological Organization (2010) WMO statement on the status of global climate in 2009. WMO No. 1055, World Meteorological Organization, Geneva

Proofs received from author(s): February 14, 2011 